University of Nebraska - Lincoln

DigitalCommons@University of Nebraska - Lincoln

2006

\title{
A method for mapping corn using the US Geological Survey 1992 National Land Cover Dataset
}

S. K. Maxwell

U.S. Geological Survey, maxwell@usgs.gov

J. R. Nuckols

Colorado State University - Fort Collins

M. H. Ward

DHHS

Follow this and additional works at: https://digitalcommons.unl.edu/usgsstaffpub

Part of the Earth Sciences Commons

Maxwell, S. K.; Nuckols, J. R.; and Ward, M. H., "A method for mapping corn using the US Geological Survey 1992 National Land Cover Dataset" (2006). USGS Staff -- Published Research. 432.

https://digitalcommons.unl.edu/usgsstaffpub/432

This Article is brought to you for free and open access by the US Geological Survey at DigitalCommons@University of Nebraska - Lincoln. It has been accepted for inclusion in USGS Staff -- Published Research by an authorized administrator of DigitalCommons@University of Nebraska - Lincoln. 


\title{
A method for mapping corn using the US Geological Survey 1992 National Land Cover Dataset
}

\author{
S.K. Maxwell ${ }^{\mathrm{a}, *}$, J.R. Nuckols ${ }^{\mathrm{b}}$, M.H. Ward ${ }^{\mathrm{c}}$ \\ a Science Applications International Corporation, National Center for Earth Resources Observation and Science, \\ US Geological Survey, Sioux Falls, SD 57198, USA \\ ${ }^{\mathrm{b}}$ Department of Environmental and Radiological Health Sciences, Colorado State University, Fort Collins, CO 80521, USA \\ c Occupational and Environmental Epidemiology Branch, Division of Cancer Epidemiology and Genetics, \\ National Cancer Institute, National Institutes of Health, DHHS, Bethesda, MD 20892, USA
}

Received 25 January 2004; received in revised form 12 July 2005; accepted 16 November 2005

\begin{abstract}
Long-term exposure to elevated nitrate levels in community drinking water supplies has been associated with an elevated risk of several cancers including non-Hodgkin's lymphoma, colon cancer, and bladder cancer. To estimate human exposure to nitrate, specific crop type information is needed as fertilizer application rates vary widely by crop type. Corn requires the highest application of nitrogen fertilizer of crops grown in the Midwest US. We developed a method to refine the US Geological Survey National Land Cover Dataset (NLCD) (including map and original Landsat images) to distinguish corn from other crops. Overall average agreement between the resulting corn and other row crops class and ground reference data was 0.79 kappa coefficient with individual Landsat images ranging from 0.46 to 0.93 kappa. The highest accuracies occurred in Regions where corn was the single dominant crop (greater than $80.0 \%$ ) and the crop vegetation conditions at the time of image acquisition were optimum for separation of corn from all other crops. Factors that resulted in lower accuracies included the accuracy of the NLCD map, accuracy of corn areal estimates, crop mixture, crop condition at the time of Landsat overpass, and Landsat scene anomalies.
\end{abstract}

(C) 2006 Elsevier B.V. All rights reserved.

Keywords: National Land Cover Dataset (NLCD); Landsat; Crop mapping; Corn; Platte River Valley; Nebraska

\section{Introduction}

Long-term exposure to elevated nitrate levels in community drinking water supplies has been associated with an elevated risk of non-Hodgkin's lymphoma (Ward et al., 1996), colon cancer (DeRoos et al., 2003), and bladder cancer (Weyer et al., 2001). Nitrate levels in private wells are often higher than in the public water supplies because they tend to be located in agricultural areas where nitrate fertilizers are used, they are shallower, and, unlike public wells, they are not monitored for nitrate. Monitoring data are generally unavailable for private wells and therefore, this population is often excluded from epidemiologic studies in spite of their higher exposure levels. However, it is possible to predict the vulnerability of private wells to nitrate contamination using a modeling approach that accounts for factors such as well depth, soil characteristics, and land use (Nolan et al., 1998). Specific information on crop type is critical to these modeling efforts because fertilizer application rates vary widely by crop type.

\footnotetext{
* Corresponding author. Tel.: +1 6055946008 ; fax: +1 6055946529.

E-mail address: maxwell@usgs.gov (S.K. Maxwell).
} 


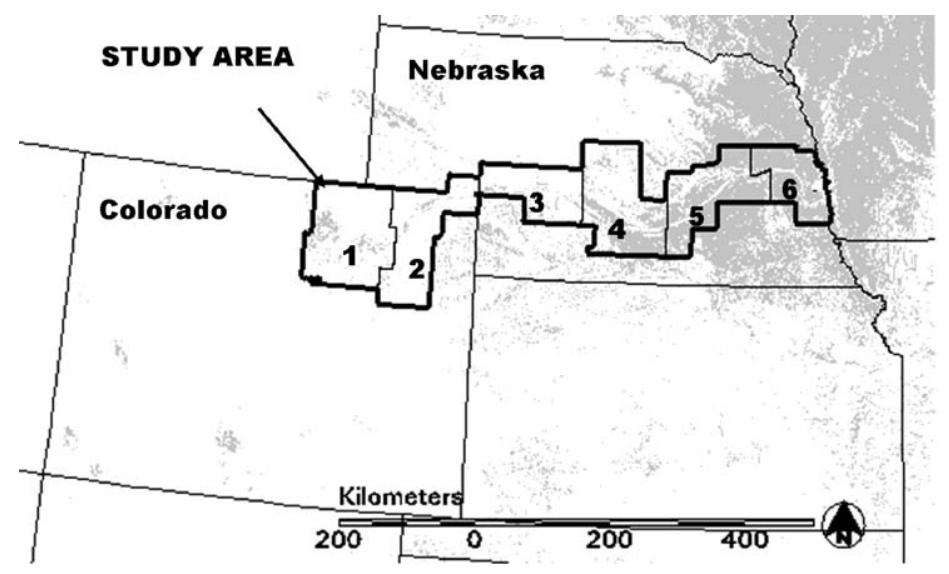

Fig. 1. Platte River Valley study area divided into six Regions. Gray shading indicates land cover area dominated by row crops $(>50 \%)$. Source: USGS National Land Cover Dataset map rescaled to $1 \mathrm{~km}$ resolution.

Traditional methods for mapping crop species from satellite imagery require ground reference data collected by field visits, surveys, or air photo interpretation to 'train' the classification algorithm or analyst. These data can be expensive and time-consuming to collect and process. We developed a classification method that uses general agricultural information readily available from the US Department of Agriculture (USDA) instead of ground reference data to refine the general 'row crop' class in the US Geological Survey (USGS) National Land Cover Dataset (NLCD) map. The objective of this study was to develop a classification method to map corn, the dominant crop in the Midwestern United States, using the 1992 USGS NLCD and the USDA National Agriculture Statistics Service (NASS) estimates of corn acreage. This paper describes the methodology we developed, and results and validation of the method applied to a 31-county study area in Colorado and Nebraska. This method was designed for use on agricultural landscapes that are dominated by a single crop.

\section{Approach}

\subsection{Study area}

The study area covers 31 counties $\left(77,321 \mathrm{~km}^{2}\right)$ along the Platte River Valley in Colorado and Nebraska. To facilitate our analysis, the counties were grouped by Landsat image acquisition date, resulting in six Regions (Fig. 1). Crops grown across the study area include a combination of row crops, small grains and hay. Row crops and small grains dominate cultivated agricultural land use in the western most Regions ( 1 and 2), whereas row crops predominate in the eastern most Regions (3-6). Corn is the most extensive crop type across the entire study area accounting for $73.7 \%$ of the total acreage of major row crops (Fig. 2). Proportion of corn to other crops for the individual Regions varies from

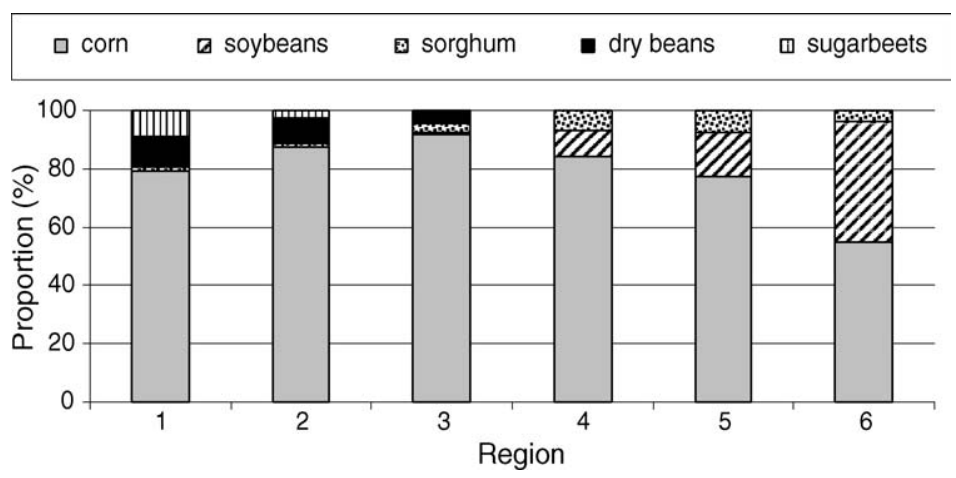

Fig. 2. Proportion of major row crop acreage for each Region in the study area. 
$54.5 \%$ (Region 6) to $91.7 \%$ (Region 3). Secondary row crops include dry beans and sugar beets in the western Regions and soybeans and sorghum in the eastern Regions.

\subsection{Datasets}

We used four datasets to conduct our study: the USGS NLCD map, original satellite imagery used to create the NLCD map, USDA NASS areal estimates for corn, and USDA Farm Service Administration (FSA) data to validate the results. The first three datasets (NLCD map, NLCD imagery, and NASS) are described in this section and the USDA FSA dataset is described under Section 2.4. The USGS NLCD map was derived from multitemporal 1992 circa Landsat Thematic Mapper imagery (leaf-off and leaf-on) along with several ancillary data sources (e.g. elevation, population density) (Vogelmann et al., 2001). A modified Anderson classification scheme (Anderson et al., 1976) was used to map up to 21 general land cover classes, four of which are specific to agricultural: hay/pasture, row crop, small grain, and fallow. The "urban/recreational grasses" class is considered to be an agricultural class in the NLCD but was not applicable in our project, therefore it was excluded from our analysis. The NLCD map is free and the Landsat images used to create it are available at a nominal cost from the USGS EROS Data Center (http://landcover.usgs.gov). We obtained the NLCD map and 10 georeferenced late summer Landsat images that completely covered our study area. All of the images were cloud-free except for a portion of Region 5 (Landsat Path 29, Rows 31 and 32) that affected approximately $10 \%$ of the study area within the image. Landsat images collected on the same overpass date were combined into one image (e.g. Path 32 Row 31 combined with Path 32 Row 32)—resulting in six images, one for each Region (Fig. 1 and Table 1). The Landsat acquisition dates were from July 14 to September 9 between 1991 and 1993 (Table 1). These late summer images represent the optimum time period for discrimination of the major crops in this Region (Bauer et al., 1979; Odenweller and Johnson, 1984; Maxwell and Hoffer, 1996).

USDA NASS areal estimates for corn were used to calibrate our classification method. NASS estimates of crop acreage are primarily from a survey of a non-probability sample of volunteer farmers, ranchers and agribusinesses conducted by each NASS State Statistical Office (Iwig, 1993). NASS does not publish information on errors associated with the estimates, however, these data are the most accurate information available for county-level crop area for each year. We used NASS estimates of corn hectares harvested for years corresponding to the Landsat imagery (Table 1). Estimates for individual counties were then aggregated to each of the six Regions.

\subsection{Classification methodology}

Instead of traditional ground reference data collected by field visits, surveys, or air photo interpretation we used NASS county estimates for corn hectares harvested to classify the NLCD row crop class into 'corn' and 'other row crops'. Our approach makes three assumptions: (1) all of the corn acreage is located within areas classified as row crop

Table 1

Characteristics of Regions within the study area

\begin{tabular}{|c|c|c|c|c|}
\hline Region number & Landsat date & Counties & Total area (ha) & Corn harvested (ha) \\
\hline 1 & $8 / 15 / 1992$ & Colorado: Adams, Morgan, Weld & 1698210 & 115663 \\
\hline 2 & 9/9/1992 & $\begin{array}{l}\text { Colorado: Logan, Sedgwick, } \\
\text { Washington; Nebraska: Deuel }\end{array}$ & 1388380 & 65723 \\
\hline 3 & $7 / 14 / 1991$ & Nebraska: Keith, Lincoln & 954372 & 91867 \\
\hline 4 & $7 / 28 / 1993$ & $\begin{array}{l}\text { Nebraska: Buffalo, Custer, } \\
\text { Dawson, Gosper, Kearney, Phelps }\end{array}$ & 1577280 & 415020 \\
\hline 5 & $8 / 19 / 1992$ & $\begin{array}{l}\text { Nebraska: Adams, Butler, Hall, } \\
\text { Hamilton, Howard, Merrick, } \\
\text { Nance, Platte, Polk }\end{array}$ & 1267510 & 596083 \\
\hline 6 & $8 / 26 / 1991$ & $\begin{array}{l}\text { Nebraska: Cass, Colfax, Dodge, } \\
\text { Douglas, Saunders, Sarpy, } \\
\text { Washington }\end{array}$ & 846302 & 293448 \\
\hline Total & & & 7732054 & 1577804 \\
\hline
\end{tabular}


in the NLCD map, (2) NASS row crop acreage estimates are accurate, and (3) the spectral properties of corn differ from other crops in the study area.

Our classification process involves two basic steps. The first step is to eliminate all non-row crop cover types (e.g. urban, forest) in the Landsat image by overlaying the NLCD map onto the Landsat images and recoding all Landsat values to zero for NLCD cover types that are not coded as row crop.

The second step is to identify corn in the remaining NLCD row crop portion of the image. We accomplished this by identifying the spectral Region representing corn within a bivariate scatter plot of Band 4 (near infrared, $0.76-0.90 \mu \mathrm{m}$ ) and 5 (middle infrared, $1.55-1.75 \mu \mathrm{m}$ ) of the Landsat image. We used Bands 4 and 5 for the bivariate spectral plot as they provided the best visual separation between major spectral clusters. Because corn is the dominant crop in every Region, the analyst can easily identify the approximate spectral Region representing corn (Fig. 3, red tones). The corn boundary (see example of boundaries in Fig. 3 below) is created using the following steps:

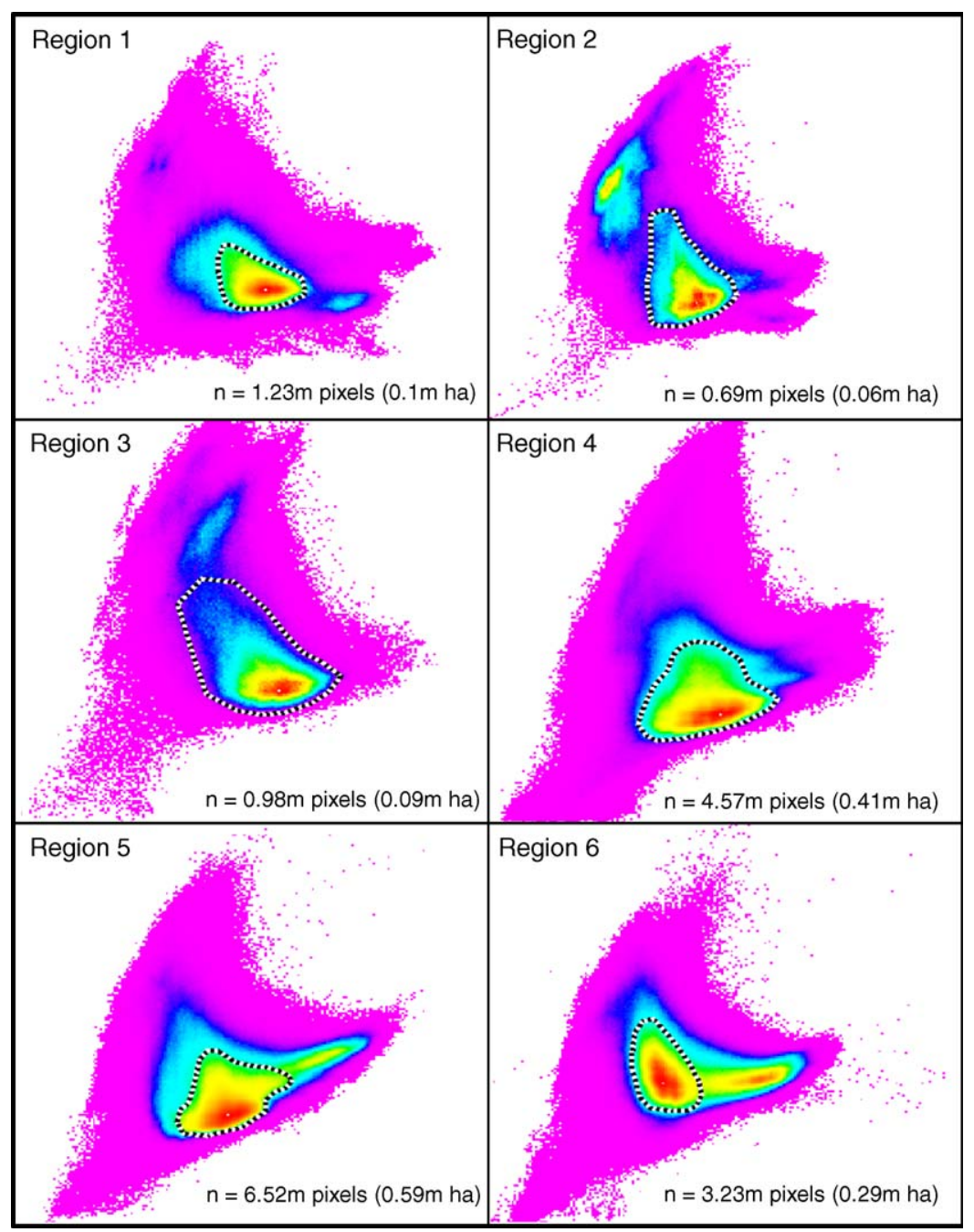

Fig. 3. Bivariate density-sliced histogram for the USGS NLCD row crop portion of the near-infrared (Band 4, $x$-axis) and middle infrared (Band 5, $y$-axis) Landsat bands for each Region. Red represents the spectral Regions with the highest frequency, yellow the next highest frequency and violet representing the lowest frequency. The dashed line represents the corn Region identified using the classification method developed. The white point represents the band combination with the greatest number of pixels (i.e. highest frequency). The number of pixels selected within the boundary are designated for each Region with number of hectares in parenthesis. 
1. Begin at the $x, y$ (Band 4, Band 5) location with highest frequency. This point represents the dominant spectral tone in the row crop class, which is corn in our case because corn is the dominant row crop in every Region.

2. Add the number of hectares represented at this $x, y$ location to an accumulated total number of hectares.

3. If the accumulated total number of hectares is greater than or equal to $95.0 \%$ of the hectares estimated by the NASS then stop, otherwise

4. Move to the next contiguous $x, y$ location with the greatest frequency and loop back to Step 2. Note: if the frequency at this location is actually greater than the previous one, it is possible that a new cluster (e.g. crop type) has been detected. In this case, the analyst may need to manually adjust the resulting boundary. See for example Region 6 in Fig. 3.

For example, the highest point in the bivariate spectral plot for Region 1 is $x=108$ (Band 4), $y=69$ (Band 5) representing 5898 pixels (531 ha) (Fig. 3, point represented as white in the center of the red area). The next highest contiguous point is $x=107, y=67$ representing 5874 pixels (529 ha). The accumulated total for the two points is 1060 ha. We continue including the next highest contiguous point until the total is greater than 109,880 ha $(95.0 \%$ of 115,663 ha of corn harvested estimated by NASS for Region 1). The process is repeated for each of the six Regions in the study (Fig. 3). All pixels in the Landsat image that have values contained within the boundary are then classified as corn. All other pixels are classified as 'other row crops'.

\subsection{Validation}

Ground reference data (location and type of crop grown), provided by FSA county offices, were used to evaluate the accuracy of the corn map. One county from each of the six Regions in our study was randomly selected. Ten Public Land Survey (PLS) Sections $(1.6 \mathrm{~km} \times 1.6 \mathrm{~km})$ were randomly selected from each of the counties where row crops represented more than $75.0 \%$ of the land area. FSA personnel were asked to identify the crop type of all large fields (>8 ha) within the Section for the year the Landsat image was collected. FSA personnel provided a photocopy of an aerial photograph with location and crop type noted. We screen digitized these fields as polygons and labeled crop type (Table 2). A sample of up to 100 pixels (approximately $8.5 \mathrm{ha}$ ) was selected from each field. Agreement between the ground reference data supplied by FSA and the corn/not corn map were calculated at the pixel level. Omission

Table 2

Validation data summary (pol.: number of polygons, pix.: number of pixels)

\begin{tabular}{|c|c|c|c|c|c|c|c|c|c|c|c|c|}
\hline & \multicolumn{12}{|c|}{ Region number } \\
\hline & \multicolumn{2}{|l|}{1} & \multicolumn{2}{|l|}{2} & \multicolumn{2}{|l|}{3} & \multicolumn{2}{|l|}{4} & \multicolumn{2}{|l|}{5} & \multicolumn{2}{|l|}{6} \\
\hline & pol. & pix. & pol. & pix. & pol. & pix. & pol. & pix. & pol. & pix. & pol. & pix. \\
\hline Corn & 27 & 2069 & 38 & 4525 & 42 & 3496 & 52 & 4193 & 63 & 5917 & 55 & 3920 \\
\hline Total other crops & 30 & 1177 & 30 & 2473 & 15 & 584 & 3 & 848 & 8 & 487 & 60 & 4314 \\
\hline Alfalfa & 2 & 40 & 1 & 44 & 4 & 127 & 1 & 16 & 1 & 33 & 10 & 570 \\
\hline Cucumbers & 1 & 63 & 0 & 0 & 0 & 0 & 0 & 0 & 0 & 0 & 0 & 0 \\
\hline Dry beans & 10 & 428 & 9 & 725 & 0 & 0 & 0 & 0 & 0 & 0 & 0 & 0 \\
\hline Fallow & 0 & 0 & 7 & 680 & 3 & 45 & 1 & 36 & 0 & 0 & 0 & 0 \\
\hline Grass & 0 & 0 & 3 & 272 & 5 & 364 & 0 & 0 & 1 & 105 & 0 & 0 \\
\hline Millet & 0 & 0 & 1 & 40 & 2 & 41 & 0 & 0 & 0 & 0 & 0 & 0 \\
\hline Oats & 0 & 0 & 0 & 0 & 0 & 0 & 0 & 0 & 0 & 0 & 3 & 113 \\
\hline Onions & 6 & 175 & 0 & 0 & 0 & 0 & 0 & 0 & 0 & 0 & 0 & 0 \\
\hline Potatoes & 3 & 61 & 0 & 0 & 0 & 0 & 0 & 0 & 0 & 0 & 0 & 0 \\
\hline Sorghum & 0 & 0 & 0 & 0 & 0 & 0 & 2 & 199 & 1 & 99 & 1 & 75 \\
\hline Soybeans & 0 & 0 & 0 & 0 & 0 & 0 & 4 & 222 & 5 & 250 & 46 & 3556 \\
\hline Sugar beets & 6 & 336 & 0 & 0 & 0 & 0 & 0 & 0 & 0 & 0 & 0 & 0 \\
\hline Sunflower & 0 & 0 & 2 & 196 & 0 & 0 & 0 & 0 & 0 & 0 & 0 & 0 \\
\hline Winter Wheat & 1 & 74 & 6 & 516 & 1 & 7 & 5 & 375 & 0 & 0 & 0 & 0 \\
\hline Total all crops & 56 & 3246 & 67 & 6998 & 57 & 4080 & 65 & 5041 & 71 & 6404 & 115 & 8234 \\
\hline
\end{tabular}


Table 3

Comparison of ground reference data (rows) to re-classified NLCD row crop class (columns)

\begin{tabular}{|c|c|c|c|c|c|c|c|c|c|c|c|c|c|c|c|c|c|c|c|c|c|}
\hline & \multicolumn{3}{|c|}{ Region 1} & \multicolumn{3}{|c|}{ Region 2} & \multicolumn{3}{|c|}{ Region 3} & \multicolumn{3}{|c|}{ Region 4} & \multicolumn{3}{|c|}{ Region 5} & \multicolumn{3}{|c|}{ Region 6} & \multicolumn{3}{|c|}{ All Regions } \\
\hline & Corn & ORC & Total & Corn & ORC & Total & Corn & ORC & Total & Corn & ORC & Total & Corn & ORC & Total & Corn & ORC & Total & Corn & ORC & Total \\
\hline Corn & 2063 & 6 & 2069 & 4371 & 154 & 4525 & 3332 & 164 & 3496 & 3709 & 484 & 4193 & 5605 & 312 & 5917 & 3474 & 446 & 3920 & 22554 & 1566 & 24120 \\
\hline Total ORC & 362 & 815 & 1177 & 69 & 2404 & 2473 & 27 & 557 & 584 & 331 & 517 & 848 & 169 & 318 & 487 & 459 & 3855 & 4314 & 1417 & 8466 & 9883 \\
\hline Alfalfa & & 40 & 40 & 1 & 43 & 44 & 5 & 122 & 127 & & 16 & 16 & & 33 & 33 & 41 & 529 & 570 & 47 & 783 & 830 \\
\hline Cucumber & & 63 & 63 & & & & & & & & & & & & & & & & 0 & 63 & 63 \\
\hline Dry beans & 352 & 76 & 428 & 39 & 686 & 725 & & & & & & & & & & & & & 391 & 762 & 1153 \\
\hline Fallow & & & & & 680 & 680 & & 45 & 45 & & 36 & 36 & & & & & & & 0 & 761 & 761 \\
\hline Grass & & & & & 272 & 272 & 15 & 349 & 364 & & & & & 105 & 105 & & & & 15 & 726 & 741 \\
\hline Millet & & & & 29 & 11 & 40 & 7 & 34 & 41 & & & & & & & & & & 36 & 45 & 81 \\
\hline Oats & & & & & & & & & & & & & & & & 50 & 63 & 113 & 50 & 63 & 113 \\
\hline Onions & 10 & 165 & 175 & & & & & & & & & & & & & & & & 10 & 165 & 175 \\
\hline Potatoes & & 61 & 61 & & & & & & & & & & & & & & & & 0 & 61 & 61 \\
\hline Sorghum & & & & & & & & & & 117 & 82 & 199 & 81 & 18 & 99 & & 75 & 75 & 198 & 175 & 373 \\
\hline Soybeans & & & & & & & & & & 214 & 8 & 222 & 88 & 162 & 250 & 368 & 3188 & 3556 & 670 & 3358 & 4028 \\
\hline Sugar beets & & 336 & 336 & & & & & & & & & & & & & & & & 0 & 336 & 336 \\
\hline Sunflowers & & & & & 196 & 196 & & & & & & & & & & & & & 0 & 196 & 196 \\
\hline $\begin{array}{l}\text { Winter } \\
\text { wheat }\end{array}$ & & 74 & 74 & & 516 & 516 & & 7 & 7 & & 375 & 375 & & & & & & & 0 & 972 & 972 \\
\hline $\begin{array}{l}\text { Total all row } \\
\text { crops }\end{array}$ & 2425 & 821 & 3246 & 4440 & 2558 & 6998 & 3359 & 721 & 4080 & 4040 & 1001 & 5041 & 5774 & 630 & 6404 & 3933 & 4301 & 8234 & 23971 & 10032 & 34003 \\
\hline Omission error & 0.3 & 30.8 & & 3.4 & 2.8 & & 4.7 & 4.6 & & 11.5 & 39.0 & & 5.3 & 34.7 & & 11.4 & 10.6 & & 6.5 & 14.3 & \\
\hline $\begin{array}{l}\text { Comission } \\
\text { error }\end{array}$ & 14.9 & 0.7 & & 1.6 & 6.0 & & 0.8 & 22.7 & & 8.2 & 48.4 & & 2.9 & 49.5 & & 11.7 & 10.4 & & 5.9 & 15.6 & \\
\hline $\begin{array}{l}\text { Overall } \\
\text { agreement } \\
(\%)\end{array}$ & 88.7 & & & 96.8 & & & 95.3 & & & 83.8 & & & 92.5 & & & 89.0 & & & 91.2 & & \\
\hline Kappa & 0.74 & & & 0.93 & & & 0.83 & & & 0.46 & & & 0.53 & & & 0.78 & & & 0.79 & & \\
\hline
\end{tabular}

ORC: other row crops. 
error was calculated as sum of correctly classified samples divided by total number of samples for each class. Overall agreement for each Region was computed as sum of correctly classified samples divided by total number of samples.

\section{Results}

Overall average agreement between the corn and other row crops class and the FSA ground reference data was 0.79 kappa coefficient for the entire study area (Table 3). Agreement for individual Regions ranged from 0.46 kappa (Region 4) to 0.93 kappa (Region 2). Omission errors for corn were relatively low for all Regions (range 0.3-11.5\%). Omission errors for the other row crop class were more variable, ranging from $2.8 \%$ to $39.0 \%$ with the highest error rates occurring in Regions 1 (30.8\%), 4 (39.0\%) and 5 (34.7\%).

A scatter plot of the ground reference samples for corn were overlaid onto the bivariate histograms and boundaries resulting from our classification method (Fig. 4, dark green points). The boundaries for Regions 2 and 6 appeared to have the best fit around the corn reference samples (i.e. most of the corn samples were included within the boundary). The other Regions' boundary area for corn had corn reference samples that were outside the boundary, other row crops within the boundaries, or both. Some of the pixels within the corn boundaries with high middle infrared values included edges of corn fields (i.e. mix of corn field and grass and/or roads). The boundary for Region 3, in particular,

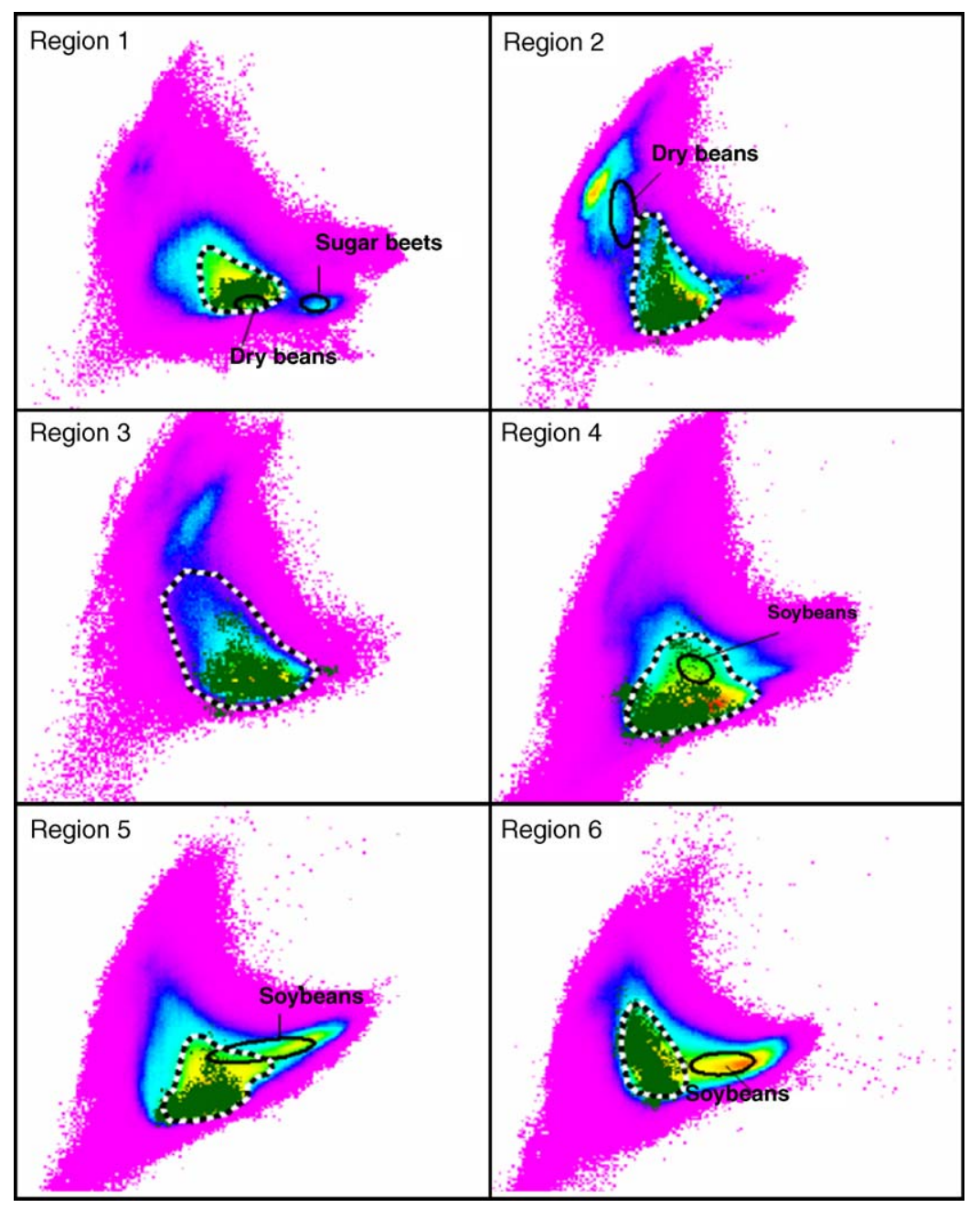

Fig. 4. Bivariate density-sliced histogram for the USGS NLCD row crop portion of the near-infrared (Band 4, $x$-axis) and middle infrared (Band 5, $y$-axis) Landsat spectral bands. The dashed line represents the corn Region identified by the analyst. The dark green points represent the ground reference data for corn. Ellipsoids represent ground reference samples for other dominant crops in the Region (mean \pm 1 standard deviation). 


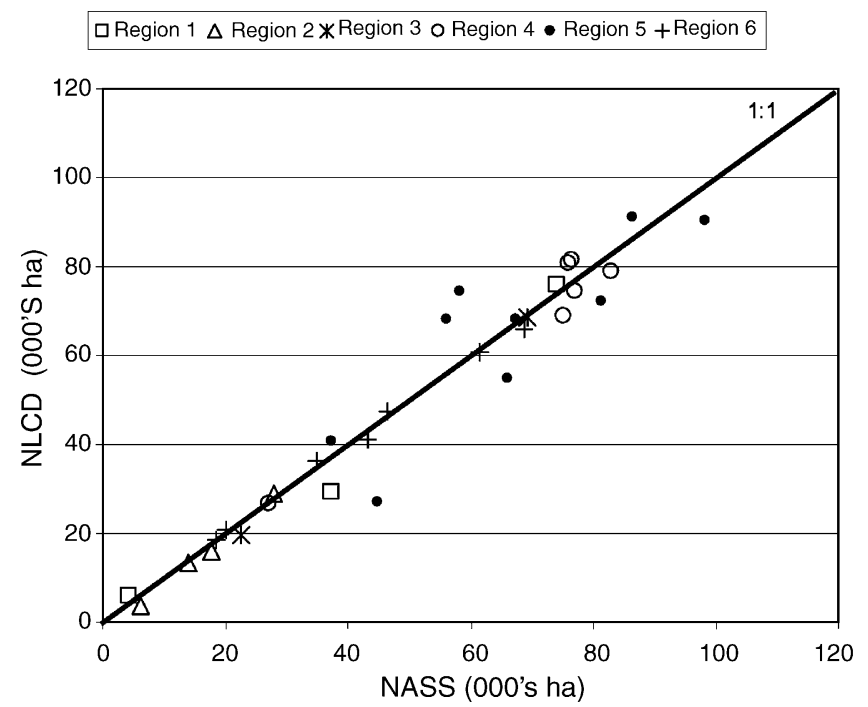

Fig. 5. Comparison of county-level NASS areal estimates for corn harvested to area of corn classified using our methodology.

extended much further into the higher middle infrared spectral area even though ground reference data did not support the inclusion of this area. Corn samples that were outside of the boundaries (see Regions 3, 4, 5 and 6) represented entire fields for the most part.

Most of the dry bean samples were misclassified as corn in Region 1 (82.2\% misclassified), yet in Region 2 there were very few misclassification errors between dry beans and corn (5.4\% misclassified) (Table 3 and Fig. 4). Almost all of the soybeans were misclassified as corn in Region 4 (96.4\% misclassified) and nearly one-third in Region 5 (35.2\% misclassified). In Region 6, where the majority of soybeans are grown, the misclassification error was much lower $(10.3 \%)$. The sample size for sorghum was too low on which to base conclusions (two fields in Region 4, one field each in Regions 5 and 6). Other row crops including sugar beets, onions, and potatoes (all in Region 1) had error rates of less than $6.0 \%$. Alfalfa (Regions 3 and 6), fallow (Regions 2 and 3), grass (Regions 2 and 3) and winter wheat (Regions 2 and 4) also had very low or no misclassification errors (less than 7.2\%).

Comparison of NASS estimates for corn to the area of corn in the refined NLCD map at the county-level demonstrated low variability overall between counties (Fig. 5). NASS estimates were highly correlated $\left(R^{2}=0.976\right)$ with NLCD estimates for counties in our study area. The highest variability occurred in Region 5, where differences ranged from $60.7 \%$ to $127.6 \%$ of the NASS estimate.

\section{Discussion}

The successful application of our methodology to other areas will depend on a number of factors including the accuracy of NLCD map for the row crop class, accuracy of the NASS corn areal estimates, the mixture of crops grown in an area, crop condition at the time of Landsat overpass, and Landsat scene anomalies. We found that one or more of these factors affected the results in several Regions in our study area.

One assumption of our method was that all corn acreage was included within the NLCD row crop class. Comparison of the FSA reference samples to the original NLCD map revealed that some corn samples were actually misclassified, primarily as hay/pasture or grassland (e.g. 2.8\% in Region 3, 4.9\% in Region 6) (Table 4). The errors were relatively small yet this may cause the corn boundary to extend farther than necessary. We suspected this was the case in Region 3 as the boundary for corn extended into spectral Regions, which are more characteristic of drier vegetation (higher middle infrared values). We re-tested our method on Region 3 using a mask that included all of the NLCD agricultural groups (row crop, hay/pasture, small grains, fallow). The boundary decreased substantially in the middle infrared band resulting in a better fit around the corn reference samples. Omission errors were only slightly altered (5.7\% for corn and $2.1 \%$ for other row crops as compared to the original estimates of $4.7 \%$ and $4.6 \%$, respectively). Another alternative might be to modify step number three to limit the boundary expansion when the frequency at the current $x, y$ location 
Table 4

Comparison of FSA ground reference samples (rows) to the original NLCD map (columns)

\begin{tabular}{|c|c|c|c|c|c|c|c|c|c|c|c|c|c|c|c|c|c|c|c|c|c|c|c|c|c|c|c|c|c|c|}
\hline & \multicolumn{5}{|c|}{ Region 1} & \multicolumn{5}{|c|}{ Region 2} & \multicolumn{5}{|c|}{ Region 3} & \multicolumn{5}{|c|}{ Region 4} & \multicolumn{5}{|c|}{ Region 5} & \multicolumn{5}{|c|}{ Region 6} \\
\hline & $\mathrm{g}$ & $\mathrm{h} / \mathrm{p}$ & $\mathrm{rc}$ & sg & o & $\mathrm{g}$ & $h / p$ & $\mathrm{rc}$ & sg & o & $\mathrm{g}$ & $\mathrm{h} / \mathrm{p}$ & $\mathrm{rc}$ & sg & o & $\mathrm{g}$ & $\mathrm{h} / \mathrm{p}$ & $\mathrm{rc}$ & sg & o & $\mathrm{g}$ & $\mathrm{h} / \mathrm{p}$ & $\mathrm{rc}$ & sg & o & $\mathrm{g}$ & $\mathrm{h} / \mathrm{p}$ & $\mathrm{rc}$ & $\mathrm{sg}$ & o \\
\hline \multicolumn{31}{|l|}{ Row crops } \\
\hline Corn & 1 & 1 & 2067 & & & 12 & 11 & 4456 & & 46 & 23 & 61 & 3398 & 8 & 6 & 69 & 11 & 4100 & 9 & 4 & 66 & 5 & 5838 & 3 & 5 & 21 & 173 & 3698 & & 28 \\
\hline Cucumber & & & 63 & & & & & & & & & & & & & & & & & & & & & & & & & & & \\
\hline Dry beans & & & 428 & & & 16 & & 692 & & 17 & & & & & & & & & & & & & & & & & & & & \\
\hline Millet & & & & & & & & 27 & 13 & & & & 41 & & & & & & & & & & & & & & & & & \\
\hline Onions & 17 & & 145 & & 13 & & & & & & & & & & & & & & & & & & & & & & & & & \\
\hline Potatoes & 7 & 4 & & & 50 & & & & & & & & & & & & & & & & & & & & & & & & & \\
\hline Sorghum & & & & & & & & & & & & & & & & & 9 & 190 & & & 1 & 7 & 90 & 1 & & & & 75 & & \\
\hline Soybeans & & & & & & & & & & & & & & & & 3 & 3 & 216 & & & & & 250 & & & 16 & 120 & 3408 & & 12 \\
\hline Sugar beets & & & 336 & & & & & & & & & & & & & & & & & & & & & & & & & & & \\
\hline Sunflowers & & & & & & & & 196 & & & & & & & & & & & & & & & & & & & & & & \\
\hline Total & 25 & 5 & 3039 & 0 & 63 & 28 & 11 & 5371 & 13 & 63 & 23 & 61 & 3439 & 8 & 6 & 72 & 23 & 4506 & 9 & 4 & 67 & 12 & 6178 & 4 & 5 & 37 & 293 & 7181 & 0 & 40 \\
\hline \multicolumn{31}{|l|}{ Summary } \\
\hline Total row crops & & & & 3039 & & & & 5371 & & & & 3439 & 3039 & & & & & & 4506 & & & & 6178 & & & & 7181 & 4506 & & \\
\hline $\begin{array}{l}\text { Total non-row } \\
\text { crops }\end{array}$ & & & & 93 & & & & 115 & & & & 98 & 93 & & & & & & 108 & & & & 88 & & & & 370 & 108 & & \\
\hline Total all & & & & 3132 & & & & 5486 & & & & 3537 & 3132 & & & & & & 4614 & & & & 6266 & & & & 7551 & 4614 & & \\
\hline $\begin{array}{l}\text { Misclassified as } \\
\text { non-row crop (\%) }\end{array}$ & & & & 3.0 & & & & 2.1 & & & & 2.8 & 3.0 & & & & & & 2.3 & & & & 1.4 & & & & 4.9 & 2.3 & & \\
\hline
\end{tabular}

All numbers represent number of pixels. (g: grassland, h/p: hay/pasture, rc: row crop, sg: small grains, o: all other classes combined). 
is insignificant compared to the total NASS estimate. For example, Step 3 would state: if the accumulated total number of hectares is greater than or equal to $95.0 \%$ of the hectares estimated by NASS or the current number of hectares just added was less than $0.01 \%$ of the hectares estimated by NASS then stop, otherwise continue to Step 4 . The value of $0.01 \%$ was established based on properties of the Region 3 bivariate histogram.

Accuracy of our method also depends on the accuracy of the NASS acreage estimates. We used a cut-off of $95.0 \%$ of the NASS estimate in our boundary delineation rule, which resulted in relatively low omission errors (less than $11.4 \%$ for all Regions). Increasing the rule to include $100.0 \%$ of the NASS estimate would probably have increased omission errors for the other row crop class as most of the corn samples that were excluded from the boundary were not the next highest contiguous spectral Regions (Fig. 4).

Using an appropriate Landsat acquisition date is another major consideration for successful separation of corn from the other dominant crop types. The August 15, 1992 Landsat date for Region 1 was not an appropriate date for separating corn and dry beans because of their spectral similarity in all bands (1 through 5 and 7). In contrast, the September 9, 1992 Landsat date for Region 2 resulted in complete separation of dry beans from corn. The September 9 date was more appropriate because the dry bean crops had senesced or had been harvested by this date, indicated by the high middle infrared spectral values (Fig. 4). Sugar beets in Region 1 were completely separated from corn in the August 15 date due to their higher near infrared values (Fig. 4). No sugar beet samples were identified by FSA in Region 2, however previous research concluded an early September date was useful for separating corn, dry beans and sugar beets (Maxwell and Hoffer, 1996).

Soybeans and sorghum are the two other dominant row crops grown besides corn in the eastern portions of our study area (Regions 4, 5, and 6). Previous studies have demonstrated successful discrimination of corn and soybeans for image dates after corn has tasseled yet prior to soybean senescence (Bauer et al., 1979; Odenweller and Johnson, 1984; Maxwell and Hoffer, 1996), which is normally between late July to late August in this Region (USDA, 1992). Sorghum has also been discriminated successfully from corn in previous work using a late August Landsat MSS image (average 93.1\% correctly classified) (Maxwell et al., 2003). All of the Landsat images covering the eastern Regions were within the optimum time frame yet omission errors were relatively high for Regions 4 (39.0\%) and 5 (34.7\%). The USDA July 25, 1993 crop progress report for Region 4 notes that corn maturation is far behind the 5-year average (29.0\% silked compared to $69.0 \% 5$-year average) indicating most of the corn was not tasseled at the time of Landsat overpass (July 28, 1993). The crop progress report also indicated soybean and sorghum progress was nearly 2 weeks behind normal, hence the image more closely reflects a mid-July vegetation growth pattern. This likely explains the lower near infrared spectral values for soybeans in Region 4 as compared to soybeans in Regions 5 and 6 (Fig. 4). We concluded that the unusual conditions during the 1993 growing season probably resulted in the higher number of soybean pixels misclassed as corn in Region 4 (96.4\% of soybeans misclassified as corn). We suggest that the USDA crop progress reports be evaluated prior to image date selection.

The crop progress report for Region 5 (August 23, 1992) indicated that 100.0\% of corn had silked and soybean harvest had not yet begun which should have resulted in good separation of corn and soybeans. Yet omission errors were relatively high for the other row crops class in Region 5 (34.7\%) and area comparisons were more variable than the other Regions (Fig. 5). Most errors were a result of soybeans misclassified as corn. We suspected a recent rainfall event may have caused the anomaly in the Region 5 image (i.e. lower middle infrared values). Two fields designated by FSA as soybeans were collected within the suspected precipitation area. These fields had much lower reflectance values in the near infrared band. Eliminating these fields resulted in $100.0 \%$ of the remaining soybean pixels being classified correctly as other row crops. There were several corn pixels having lower near IR values that were also within the precipitation area. These pixels were not included in the boundary delineated for Region 5 (Fig. 4). One suggestion to eliminate these errors would be to segment and analyze the Regions separately.

The boundaries resulting from our methodology would be difficult, if not impossible, to represent using statistical parameters (mean, standard deviation, covariance). In previous work, we developed a parametric classification method for discriminating corn from other crops using four counties in Region 5 for our study area. The method resulted in a similar high overall agreement against ground reference data (92.2\%; Maxwell et al., 2003). The study area in the current project was much larger and we suspected that crop irrigation practices may impact the ability to effectively classify corn (irrigated and non-irrigated) from other crops using a parametric approach and therefore wanted to test a non-parametric method. The scope of this effort did not include analysis and identification of irrigation practice as a separate class. We did, however request that FSA personnel label samples as irrigated or non-irrigated. A preliminary review of these samples indicated a spectral difference between irrigated and non-irrigated corn. Irrigated corn tended 
to have equal yet higher variability in Band 4 (near infrared) values and lower and less variability in Band 5 (middle infrared) values. This supports the generally 'pear-shaped' boundaries resulting from the delineation process. This shape would not be possible to characterize with statistical parameters.

Selection of which bands to use will also be a consideration. Our methodology was tested only on the near infrared (Band 4) and middle infrared (Band 5) of the Landsat Thematic Mapper sensor as we found these two bands to be the best to visually separate dominant spectral Regions. The user should evaluate which bands to select for their specific study area as the optimum band combination may depend on crop mixture and image acquisition date. For example, using Band 3 (visible) and Band 4 (near infrared) may provide better results. We anticipate the near infrared and middle infrared band selection to be appropriate for the Landsat Thematic Mapper and Enhanced Thematic Mapper sensors for areas in the Midwest where corn is a dominant crop.

\section{Conclusions}

We developed a method to refine the NLCD map row crop class to corn and other row crops to support a nitrate exposure assessment study in the Colorado and Nebraska Platte River Valley. Development of a cost-effective method was essential due to the large regional extent of the study area and budget constraints. Our method integrated USDA NASS county-level areal estimates for corn and a non-parametric approach to delineate the corn spectral Region in a bivariate feature space image of Landsat Bands 4 (near infrared) and 5 (middle infrared). Agreement between ground reference data and the resulting corn and other row crop classes ranged from 0.46 to 0.93 kappa for the six different Landsat image dates we tested (July 14, July 28, August 15, August 19, August 26, September 9). Accuracy of the corn and other row crop map was dependent on several factors: accuracy of the original NLCD map, accuracy of the NASS areal estimates, crop mixture, crop condition at the time of Landsat overpass, and Landsat scene anomalies.

Prior to applying this methodology we recommend the following:

- Compare the NLCD to NASS estimates and visually assess the row crop areas in the Landsat imagery to identify and possibly correct for anomalies.

- Ensure the Landsat image date is appropriate for optimum separation of corn from the other major crops. An early September date was better for separating corn from dry beans in the western Regions (Regions 1 and 2). Late July to late August image dates were successful for separating corn from soybeans in the eastern Regions (Regions 4, 5 and 6).

- Review the results of the boundary delineation process for reasonableness and correct manually if necessary.

\section{Acknowledgements}

We thank the USDA Farm Service Agency in Nebraska for providing the ground reference data used in this project. This study was conducted in part through support by the National Cancer Institute, Subcontract No. B138-01, Prime contract N01-CP-33000 and US Geological Survey contract 1434-CR-97-CN-40274.

\section{References}

Anderson, J.R., Hardy, E.E., Roach, J.T., Witmer, R.E., 1976. A land use and land cover classification system for use with remote sensor data. USGS Professional Paper 964. US Geological Survey, Reston, VA, p. 28.

Bauer, M.E., Cipra, J.E., Anuta, P.E., Etheridge, J.B., 1979. Identification and area estimation of agricultural crops by computer classification of Landsat MSS data. Remote Sens. Environ. 8, 77-92.

DeRoos, A., Ward, M.H., Lynch, C., Cantor, K.P., 2003. Nitrate in public water supplies and risk of colon and rectum cancers. Epidemiology 14, 640-649.

Iwig, W.C., 1993. The National Agricultural Statistics Service County Estimates Program. In: Subcommittee on Small Area Estimation, Federal Committee on Statistical Policy, Statistical Policy Working Paper 21, Indirect Estimators in Federal Programs. US Office of Management and Budget, Washington, DC, (Chapter 7).

Maxwell, S.K., Hoffer, R.M., 1996. Mapping agriculture crops with multi-date Landsat data. In: Proceedings of the National ASPRS/ACSM 1996 Annual Convention, Baltimore, MD, pp. 433-443.

Maxwell, S.K., Nuckols, J.R., Ward, M.H., Hoffer, R.M., 2003. An automated approach to mapping corn from Landsat imagery. Comput. Electron. Agric. 43, 43-54.

Nolan, B.T., Ruddy, B.C., Hitt, K.J., Helsel, D.R., 1998. A national look at nitrate contamination of ground water. Water Cond. Purif. 39 (12), $76-79$. 
Odenweller, J.B., Johnson, K., 1984. Crop identification using Landsat temporal—spectral profiles. Remote Sens. Environ. 14, $39-54$.

USDA, 1992. Weekly Weather and Crop Bulletin for 1992. National Agricultural Statistics Service, Agricultural Statistics Board, website: http://usda.mannlib.cornell.edu/reports/waobr/weather/.

Vogelmann, J.E., Howard, S.M., Yang, L., Larson, C.R., Wylie, B.K., van Driel, N., 2001. Completion of the 1990s National Land Cover Data set for the conterminous United States from Landsat Thematic Mapper data and ancillary data sources. Photogrammetric Eng. Remote Sens. 67, $650-662$.

Ward, M.H., Mark, S.D., Cantor, K.P., Weisenburger, D.D., Correa-Villasenor, A., Zahm, S.H., 1996. Drinking water nitrate and risk of non-Hodgkin's lymphoma. Epidemiology 7, 465-471.

Weyer, P.J., Cerhan, J.R., Kross, B.C., Hallberg, G., Kantamneni, J., Breuer, G., Jones, M., Zheng, W., Lynch, C.F., 2001. Municipal drinking water nitrate level and cancer risk among older women: the Iowa Women's Health Study. Epidemiology 11, 327-328. 